\title{
RAILROAD INFRASTRUCTURE SIMULATOR
}

\author{
Marcelo Moretti Fioroni \\ Luiz Augusto G. Franzese \\ Paragon Consulting Solutions. \\ R. Clodomiro Amazonas $1435-5^{\text {th }}$ \\ São Paulo SP $104537-012$ BRAZIL
}

\author{
Naguissa Yuri Hiramatsu Pereira \\ Marcelo Neder Machado \\ MRS Logística S.A. \\ Av. Brasil, 2001 - Juiz de Fora - MG \\ 29163-970, BRAZIL
}

\begin{abstract}
The railroad is one of the best options for long distance and high volume transportation. Many studies have been developed to determine the best way to use the available infrastructure (tracks, locomotives, etc.) or the best procedures to block trains or schedule its departures. This study presents an experience made with a reusable simulation tool specially designed to evaluate the impact of infrastructure changes on rail lines or load / unload terminals. Some aspects of this simulation tool are presented, and an experiment made with a real rail network is described.
\end{abstract}

\section{INTRODUCTION}

Railroad studies are very important nowadays, where companies try to reduce costs and governments try to increase the economy, connecting isolated productive areas to the customer market.This kind of study has many branches, many of them provided by operations research, and some very new, like computational discrete event simulation, which followed the great growth of computer technology on past years. The simulation, that was once made manually, now is powered by robust computational tools.

Many aspects of the railroad transportation have been studied with simulation tools, like rail yard operations (Fioroni et. al., 2004), train movement at rail networks (Franzese et. al., 2003) (Middelkoop and Bouwman, 2001) or even crew assignments (Guttkuhn et. al., 2003).

Despite all technology, the great challenge at these studies is the right representation of train behavior, and the human decisions involved on conflict resolutions. Model the human decisions on a computational tool is always a hard task. The usual way to approach the problem is to find the most common rules that guide the process, or adopt simpler rules.

For example, on many train movement simulations, the modeler chooses to do not model the train conflicts in deep detail, using an increased movement time to represent it. This turns the modeling task easier, but at cost of losing results accuracy. And some studies cannot be done with models that adopt such detail level, like lines or crossing yards expansion.

The tool presented was developed using ARENA software, and can be used to represent any cargo railroad, since it was designed to achieve detailed and customizable infrastructure. A case study with a real rail network is presented to illustrate results obtained.

\section{INFRASTRUCTURE DETAIL LEVEL}

The kind of rail line supported by the model is very common on Latin America and several large countries. It is essentially constituted by single line segments and crossing yards, that are small segments of double lines. The crossing yards are used by the trains to avoid collision in case of two trains moving on opposite directions. So, one of the trains must stop at the crossing yard and wait for the other to pass.

The algorithm used by the model is described by Fioroni and Botter (2004), and were developed to support the following kinds of rail line structure:

- $\quad$ Single and double line;

- Non-signalized line (line sections where the train cannot stop for traffic reasons);

- Signalized line, where the train can stop at "section breaks" that are segments of bigger lines where the train can stop for traffic reasons;

- All lines bidirectional;

- Special activity lines at the yards. Lines where the train can stop for some time, to load, unload or do maintenance;

- Crossing yard length (long trains cannot stop on some yards).

The following picture shows that structure representation (Figure 1). 
Fioroni, Franzese, Pereira, and Machado

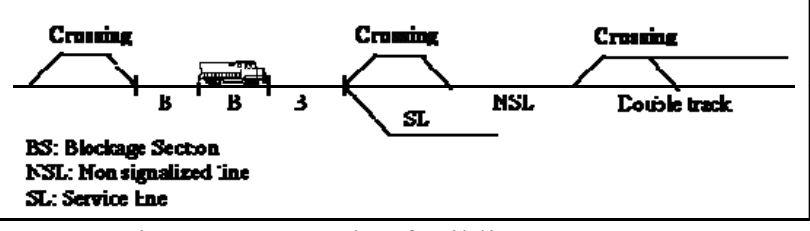

Figure 1: Example of rail line structure

To model a rail network under this detail level, the movement algorithm must be able to avoid complex traffic situations, like the described below. Two trains moving to one direction face two trains moving from the opposite direction under a single line. This conflict solution is presented on Figure 2:

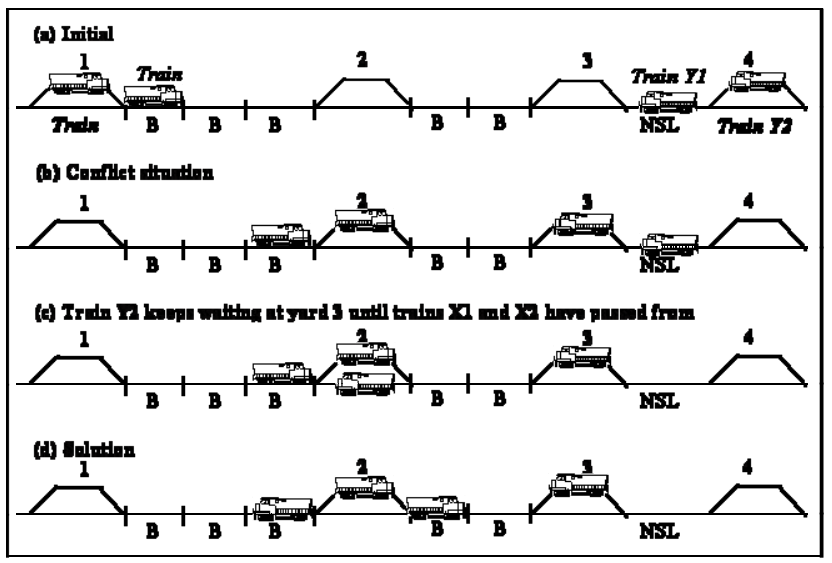

Figure 2: Traffic conflict solution

\section{THE RAILROAD SIMULATOR}

The railroad transportation system demands large infrastructure investments. This is a problem, especially for the less developed countries, because they need most efficient transportation modals, but has low monetary resources to invest on railroads. Under this situation, is imperative to invest wisely, and a tool to support the decision of where or what to do first is very important.

The tool presented here can represent the most common structures on a cargo rail network, and the most common types of trains that run on the network.

Some of the inputs required are:

- $\quad$ Rail terminals, with the individual number of load / unload or activity lines;

- Connection lines between terminals, and it's characteristics;

- Transit times between terminals for each type of train;

- Number of trains and it's path on the network,

- Probability of maintenance on a terminal or line, and the time of that maintenance;

- General information about the height of the train and it's cargo;
- Number of locomotives available on each fleet of different locomotive types.

Some of the outputs provided are:

- Total cargo dispatched;

- Number of load and unload operations;

- Number of trains moved on each line and direction;

- Time spent on each terminal, waiting for another train to move from opposite direction (trespassing operation);

- Number of locomotives used for each fleet;

- Among many others.

These outputs are enough to make decisions for investment on line duplications, terminal expansions of locomotive acquisitions. The whole system works using a corporate user interface, showed in Figure 3.

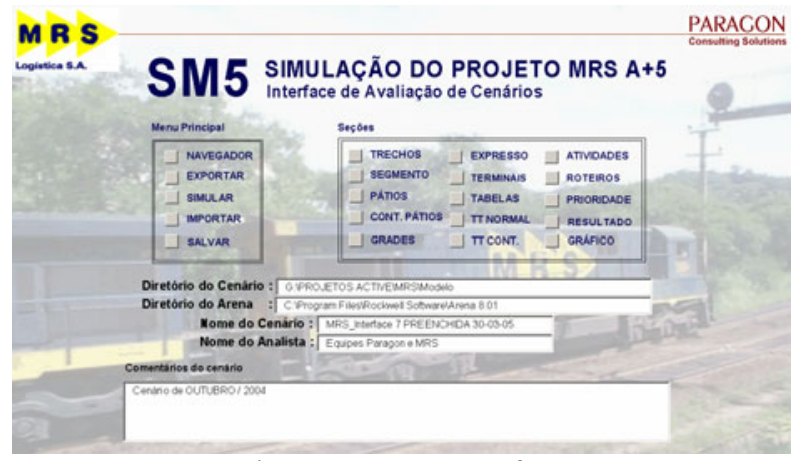

Figure 3: User Interface

The model is built on the Rockwell Software's ARENA simulation package, and MS Access. Results collection is made through individual log data for each train, what mimic real traffic control systems. (Figure 4).

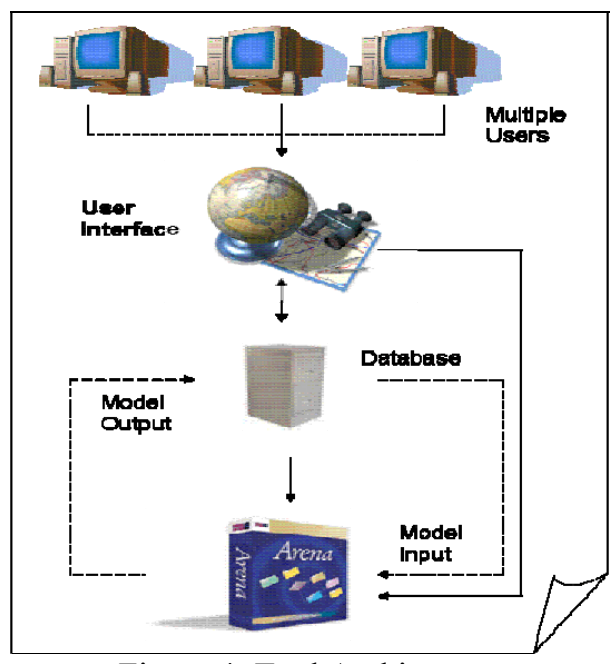

Figure 4: Tool Architecture 


\section{CASE STUDY}

The MRS Logística is one of the most important railroad companies in Brazil. Its network is constituted mainly by single lines and it's most important product is the iron coal transportation. The entire network is presented on Figure 5.

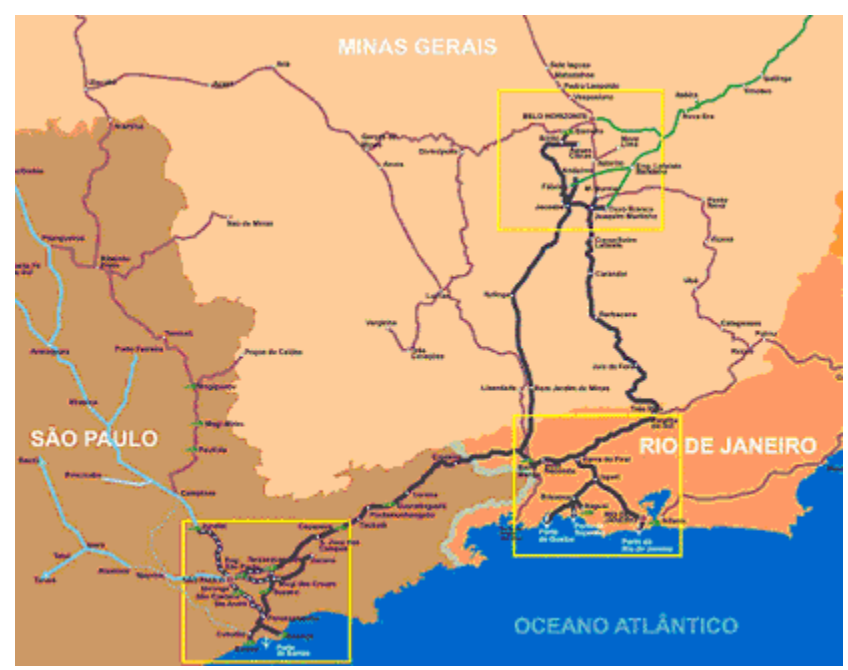

Figure 5: MRS rail network map

Facing the challenge to follow a market growing, the company needed a study to certify that the investments planned for the next years would be really effective. The entire network was represented in the simulation model, and well as several types of trains (coal trains, general cargo, express) wand load / unload terminals. Some customization was made to the model, to represent some specific activities of the company, that consist on schedule the empty cargo trains among some number of loading terminals with individual parameters. The details of the animation are presented on Figure 6 (with the trains indicated as colored balls) while the animated interface of the network is presented in Figure 7.

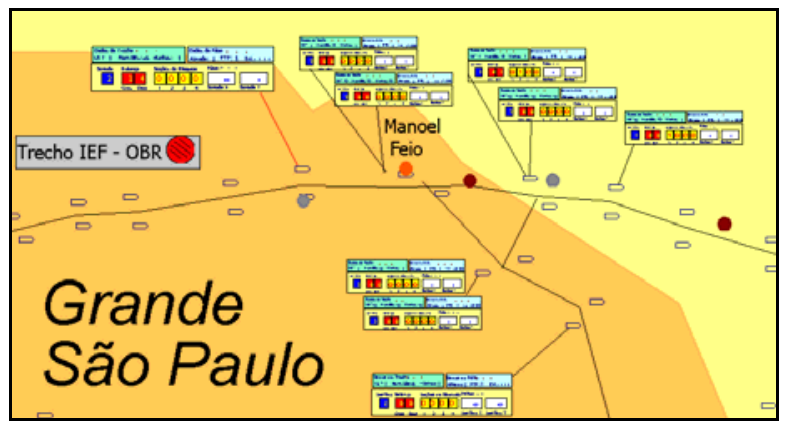

Figure 6: Animation detail

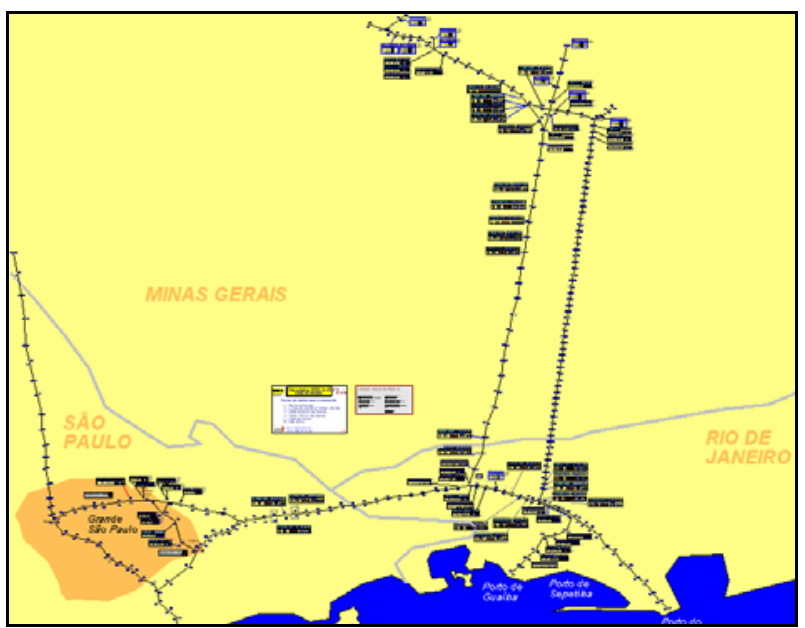

Figure 7: Rail network animation

\section{RESULTS}

The model was first simulated under the present situation of the network infrastructure and was successful to represent it with a very high accuracy.After that, several scenarios of future investment plans were experimented on the simulator, providing safe decisions to MRS.

The model was prepared to generate results on the same format of those used on the management process department of MRS Logística, to help evaluate the simulation performace of many scenarios. Based on the "transported tons." indicator, the number of replications was determined as 10 , to reach the precision of $90 \%$. This indicator is presented at figure 8, and other indicators at figure 9. Each replication represents 30 days of company operation and the first 5 days are considered as an warm-up period.

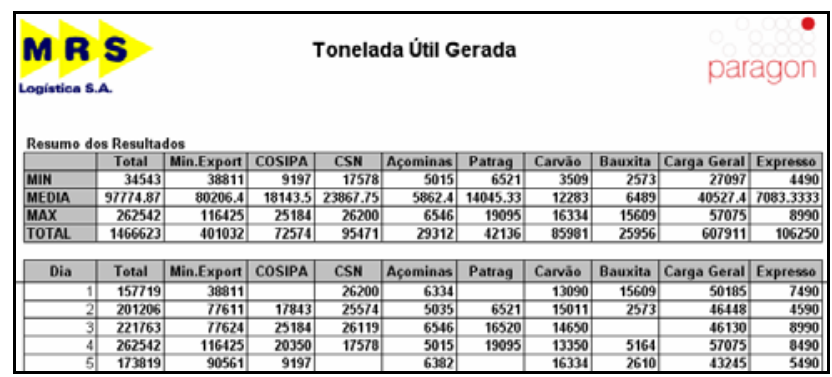

Figure 8: Report of total tons. transported

Adopting these procedures, the company simulation team made several tests, validating the model. Aditionally, the team used the animation interface to check and validate the movement rules of the implemented algorithm. The confidence level of the results provided safe analisys and decision taking for the future investments. 
Fioroni, Franzese, Pereira, and Machado

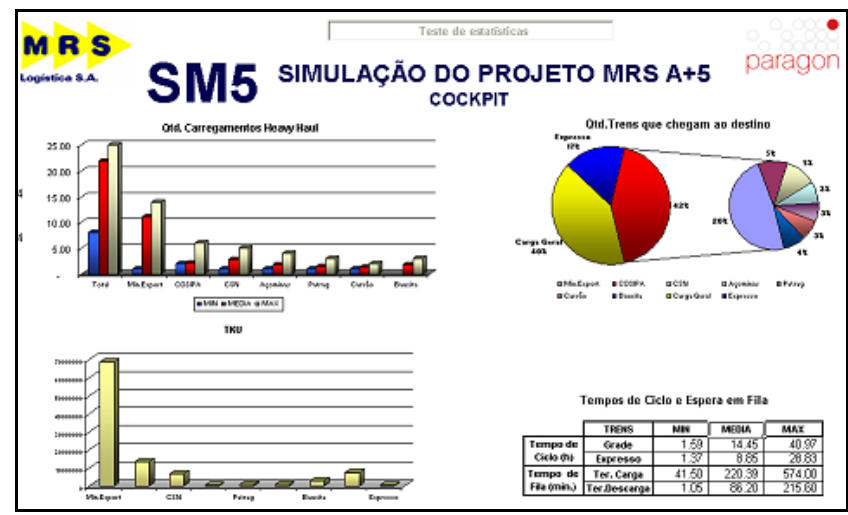

Figure 9: Main indicators summary

\section{CONCLUSIONS}

The results obtained by the experiment proved that is possible to simulate rail network with enhanced level of detail using a reusable and customizable tool, based on commercial simulation products. The tool was able to represent all aspects of the network behavior and components using its default components. And the individual aspect of the company was tested with few customizations. The model can be used to do tactical analisys, like the reconfiguration of train routes, procedure that can avoid some kind of investments, saving the rail network to have traffic bottlenecks

The conclusion is that the tool can represent most cargo rail networks, even with individual aspects of each company. It is accurate enough to provide good decision support and can be used by any rail company with investment plans on infrastructure.

\section{ACKNOWLEDGEMENTS}

The authors thanks to MRS Logística for providing data for that experiment and continued support on this project.

\section{REFERENCES}

Fioroni, M. M., Botter, R. C., An Algorithm for Train Movement Simulation, Proceedings of the ICIL'2005, p.113-120, Montevideo, Uruguay, 2005.

Fioroni, M. M., R. C. Botter, F. M. Pompermayer, L. A. G. Franzese, Estudo Estratégico da Infra-estrutura do PátioFerroviário de Tubarão através de Simulação, Proceedings of the XVIII Anpet, Florianópolis, Brazil, November 2004.

Franzese, L. A. G., Fioroni, M. M., R. C. Botter, Railroad Simulator on Closed Loop, Proceedings of the 2003

Winter Simulation Conference, New Orleans, U.S.A., December 2003.

Guttkuhn, R., J. Walker, M. Moroz, A Discrete Event Simulation for the Crew Assignment Process in North America Freight Railroads, Proceedings of the 2003
Winter Simulation Conference, New Orleans, U.S.A., December 2003.

Middelkoop, D., M. Bouwman, SIMONE: Large Scale Train Network Simulations, Proceedings of the 2001 Winter Simulation Conference, U.S.A., December 2001.

\section{AUTHOR BIOGRAPHIES}

LUIZ AUGUSTO G. FRANZESE is a simulation consultant with a Production Engineering and MSc. in Logistics background, who has completed almost 150 successful projects with simulation. Founded PARAGON Tecnologia in 1992, the pioneer and leading consulting company in simulation in South America. Has trained more than 1,200 professionals in simulation. He can be contacted by email at $<$ paragoneparagon. com. br $>$

MARCELO MORETTI FIORONI is a simulation consultant with an Electrical Engineering degree, MSc. in Manufacturing and under Logistics PhD program. Has participated in almost 150 successful projects with simulation. Co-founder of PARAGON Tecnologia in 1992, the pioneer and leading consulting company in simulation in South America. Teaches OR and Simulation at FPJ and FISP. Has trained more than 1,200 professionals in simulation. $\mathrm{He}$ can be contacted by email at $<$ marcelo@paragon.com.br>

NÁGUISSA YURI HIRAMATSU PEREIRA is a senior rail simulation analyst at MRS, with MBA in Management and Economy degree. Se can be contacted by email at <nag@mrs.com.br>

MARCELO NEDER MACHADO is a simulation engineer at MRS. He can be contacted by email at $<$ mnmamrs. com. br $>$ 